\title{
Construction of a New Type of Modular Tubular Machine
}

\author{
Dan-Cristian Popa ${ }^{a}$, Vasile-loan Gliga ${ }^{b}$ and Loránd Szabóc \\ Technical University of Cluj-Napoca, 400114 Cluj-Napoca, 28 Memorandumului str., Romania \\ aDan.Cristian.Popa@emd.utcluj.ro, bgliga_vasile@hotmail.com, 'Lorand.Szabo@emd.utcluj.ro
} Keywords: tubular machine, transverse flux, variable reluctance, modular topology, SMC core,
non-magnetic spacer, prototype.

\begin{abstract}
A new type of tubular machine in modular construction that can work either like motor or generator is presented in the paper. It belongs to the transverse flux machines' class and operates based on the variable reluctance principle. Two topologies of the machine, with and without permanent magnets (PM), are approached here. A prototype of the tubular machine with electromagnetic excitation, having a stator core built from laminated sheets and the mover core made of soft magnetic composite material, was built and is shown in the paper. The use of the new soft magnetic composite material, Somaloy $700 \mathrm{HR}$, having 3D magnetic isotropy, brings important advantages in building the structure. The innovative construction, implying the alternation of the magnetic pieces called modules with no-magnetic spacers, has very good performances. A prototype of this machine was built and a test bench equipped with control and monitoring devices in order to perform experimental tests. Some possible applications showing the potential of the proposed machine are also presented.
\end{abstract}

\section{Introduction}

The proposed machine is a novel tubular structure as a modular construction [1], operating based on the variable reluctance machine principle. The flux lines have transverse paths with respect to the mover movements [2]. From this reasons it can be named a Modular Tubular Transverse Flux Reluctance Machine (MTTFRM).

Variable reluctance linear tubular machines seem to be good solutions, used either like motors or generators, for precise industrial linear positioning systems, membrane pumps, healthcare [3], short track transfer system drives, electromagnetic valve actuators [4], transportation, vibrators or active shock absorbers [5], automotive actuator [6], aerospace actuators, launching systems in military or sports applications, driving of the elevator doors [7], Ocean Wave Energy Generator [8, 9] etc. This paper presents the topology of such machines used as motors or generators and their construction technology.

\section{MTTFRM Topologies}

Function of the topology, MTTFRM can work in both operating regimes: motor and generator. In the first case, the machine can be with passive or active mover, in the second case by using $\mathrm{NdFeB}$ permanent magnets. The generator regime can be obtained only at the machine with an active mover that is used in order to produce energy $[8,9]$.

The flat-type linear machines have the shortcoming of a high normal force between the two armatures. The great advantage of the tubular machines is the compensation of all the attraction forces on the circumference of the air-gap due to the machine's radial symmetry [1,3].

Hence the only force that can be measured at the tubular structures is the traction force. This is produced in the case of MTTFRM with passive mover, like at the modular flat-type linear structure, by a single supplied phase of the motor.

The MTTFRM has a stator with salient poles, similar to the SRM, with coils wound on each of them, and a mobile armature or mover connected to a load. The mover makes displacements in successive steps to the left or to the right depending on the supplied phase of the stator. 
The precision of the MTTFRM movement is determined by the number of stator phases and of the value of the stator pole pitch.

The stator, Fig. 1, has minimum three phases in order to obtain continuous movement of the mobile part [1]. It is built from ferromagnetic pieces which constitute modules of each phase separated by nonmagnetic rings called spacers. The displacement step is given by the pole pitch, which must be the same both on the stator and the mover, to phase number ratio.

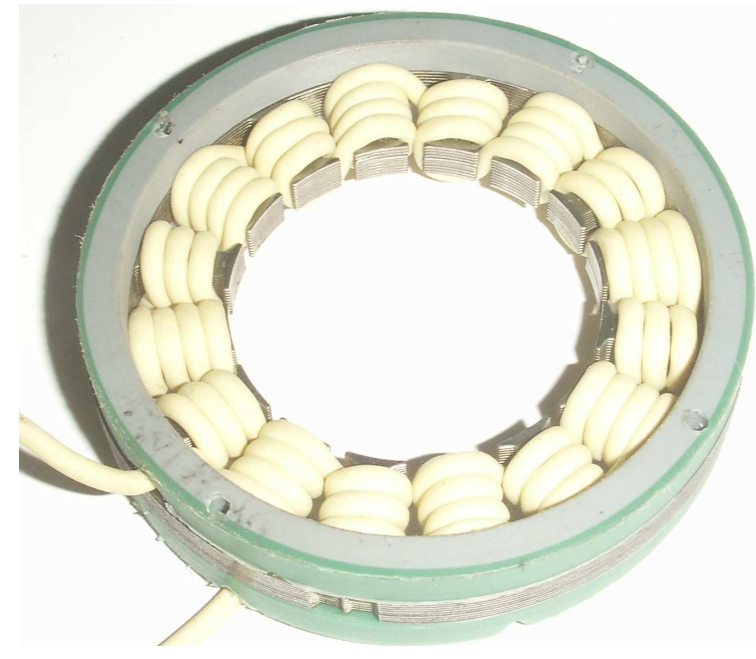

a)

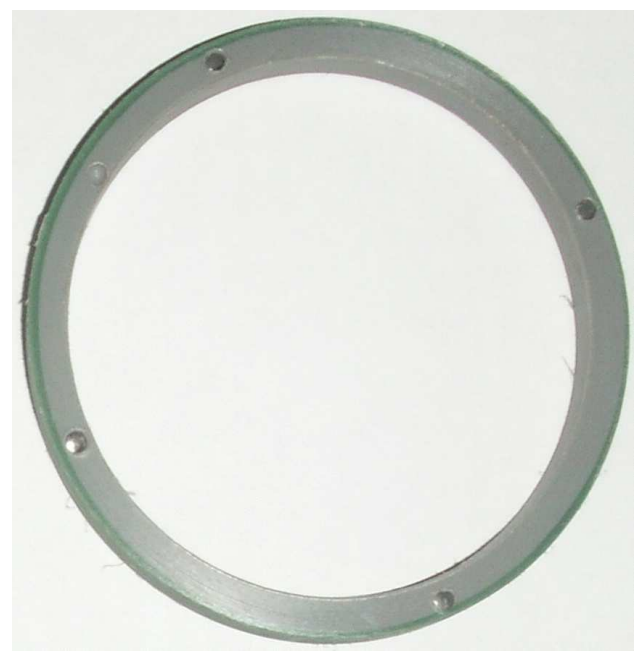

b)

Fig. 1. Component parts of the stator:

a) stator phase built from two modules; b) stator spacer.

The length of the stator and the need to use complex drivers for the control of the machine are the factors that limit the number of phases of the MTTFRM. Therefore, usually three or four phases are the variants that are considered for such tubular machine.

The mover, Fig. 2, is built from a number of ferromagnetic rings separated by nonmagnetic spacers. Both the rings and the spacers are mounted on a non-magnetic shaft. This arrangement of the mover forces the field lines to close from the stator module to the ring of the mover in a transverse direction, generating tangential force between the magnetic pieces of the stator and of the mover. The number of successive rings of the mover gives in fact the length of the whole machine.

The mover has two degrees of freedom. The first is axial direction left and right, and the second is the pivoting motion. Only the translation motion is analyzed in the paper. However, machine topologies having translation and rotation movement simultaneously can be designed, but they require a different control strategy than presented here [10].

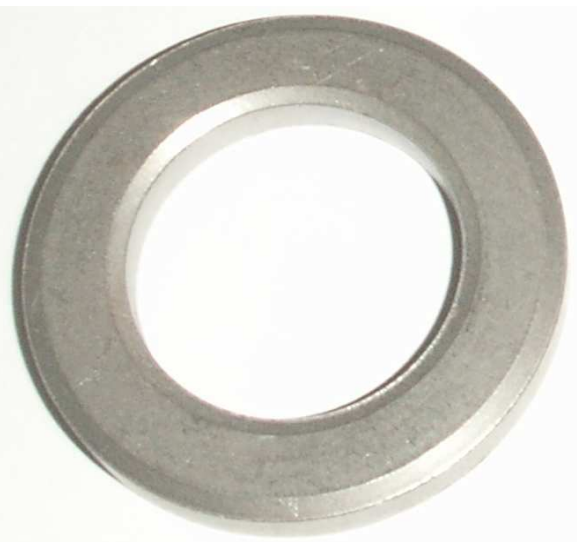

a)

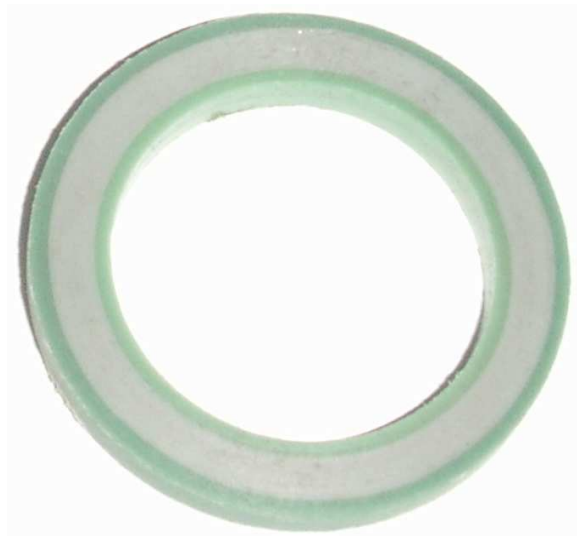

b)

Fig. 2. Component parts of the mover:

a) magnetic piece from the mover; b) spacer from the mover. 
The stator and mover ferromagnetic parts can be made both of steel sheets and soft magnetic composites (SMC).

Each phase can be built from a number of modules, connected series or parallel. In order the machine to work properly, the phases of the stator must be shifted by $s_{m}+\tau / N$ [1], where $s_{m}$ is the width of the mover spacer, $\tau$ is the pole pitch and $N$ is the number of stator phases. The necessary shifting between the modules is assured by corresponding non-magnetic spacers.

A $90^{\circ}$ longitudinal section of a three phase MTTFRM structure with two modules per phase is given in Fig. 3. A transversal section through the machine, evidencing the placement of the coils around each pole, is presented in Fig. 4.

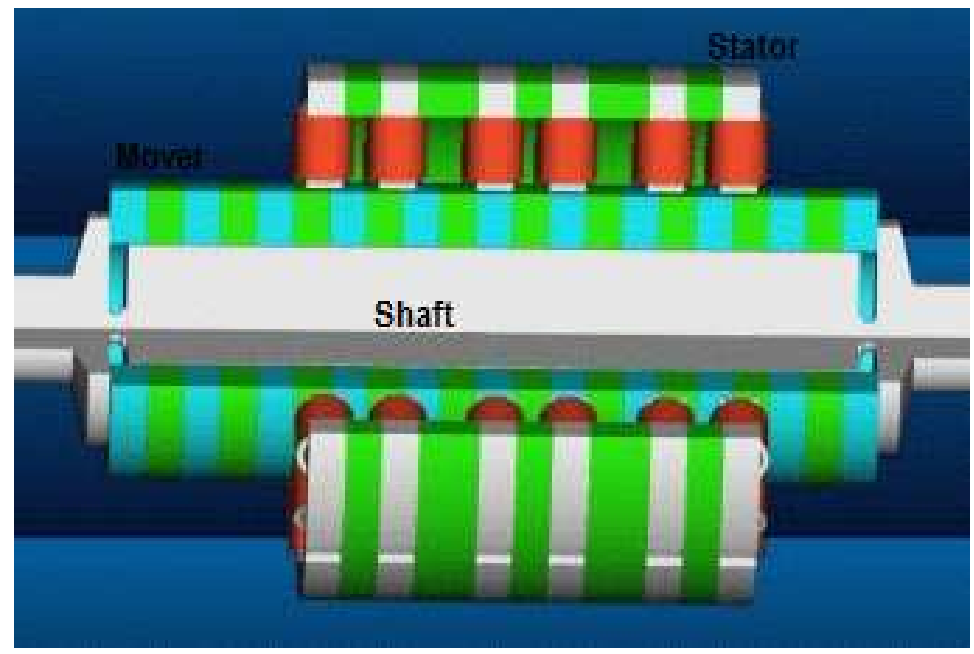

Fig. 3. Longitudinal section of MTTFRM

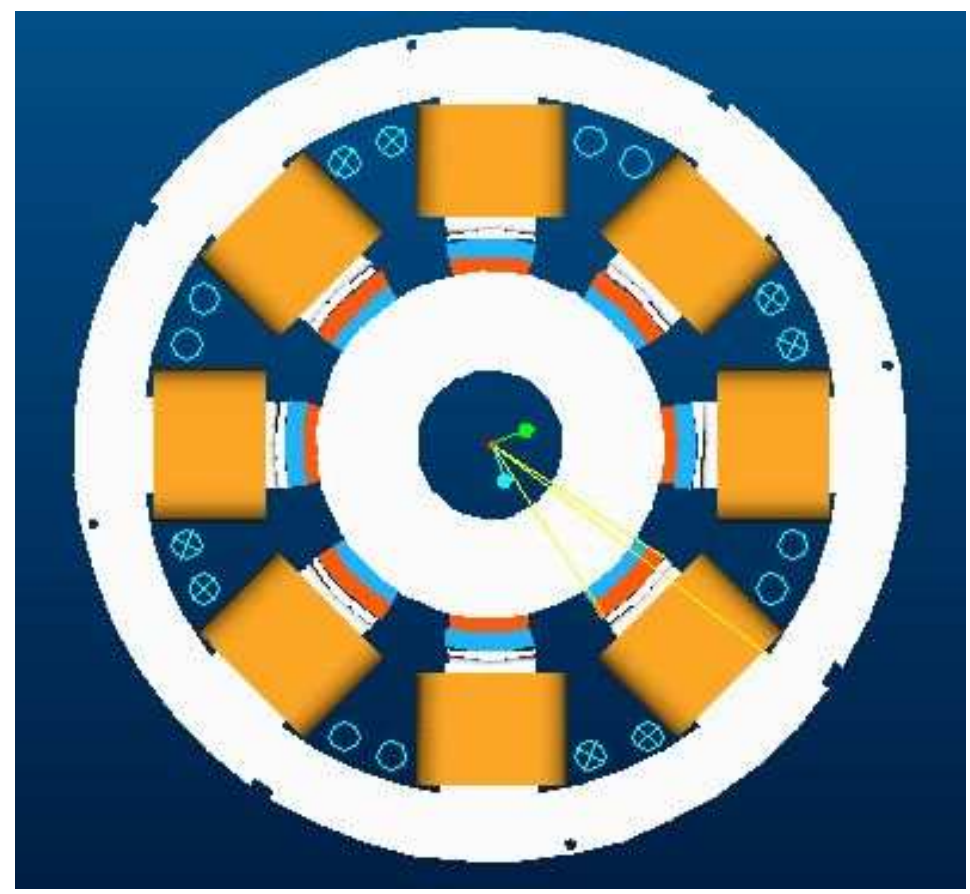

Fig. 4. Transversal section of MTTFRM

For the construction of a MTTFRM with active mover the insertion of permanent magnets in the mobile armature must be considere, as presented in Fig. 5. This structure, besides benefiting from the energy given by the permanent magnets, has several disadvantages, the most important being the more complicated construction, the greater height of the machine, the sensitivity of the magnets when the machine is operated in more demanding environments and the price. But mainly due to the construction difficulties and the bigger price, the attention of the authors was focused on the first variant presented, which was also built. 


\section{Innovation for Sustainable Development}

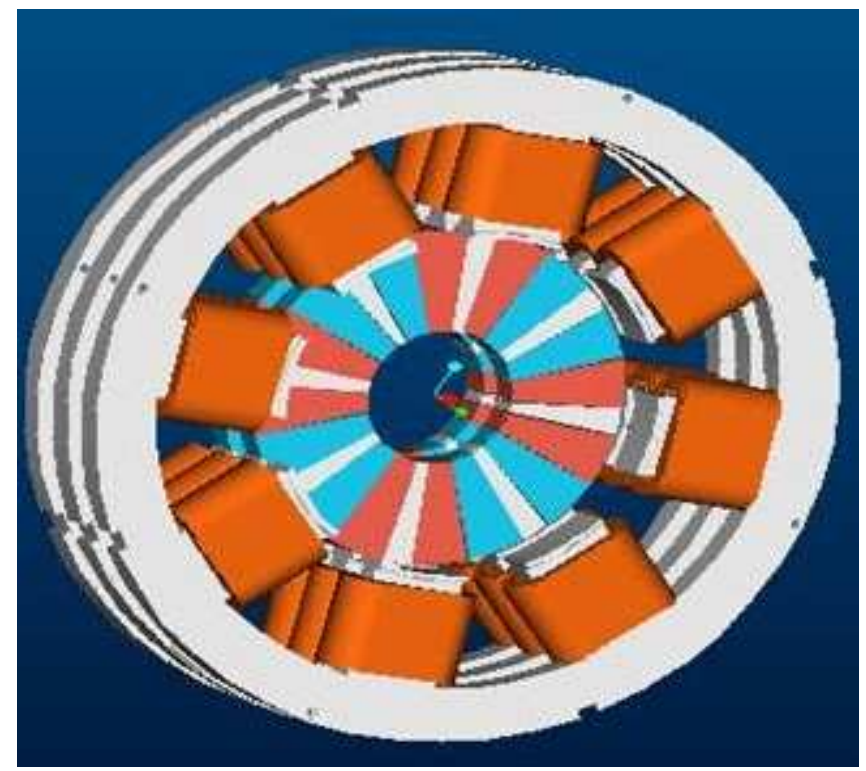

Fig. 5. Three phase MTTFRM with active mover

\section{MTTFRM with Passive Mover}

After presenting the possible topologies of the tubular transverse flux variable reluctance machine, the attention is focused here on the structure with passive mover operating as motor. The operating principle is illustrated briefly by explaining the succession of operation regarding the control of the windings of the phases.

When supplying a winding of a phase the teeth of that module will tend to align with the teeth of the mover. So, only a single phase is energized at each time moment and consequently only a single phase is generating traction force. The total force is the one given by a single module multiplied by the number of modules of a phase. The way the flux lines are closing from the stator to the mover is presented in Fig. 6.

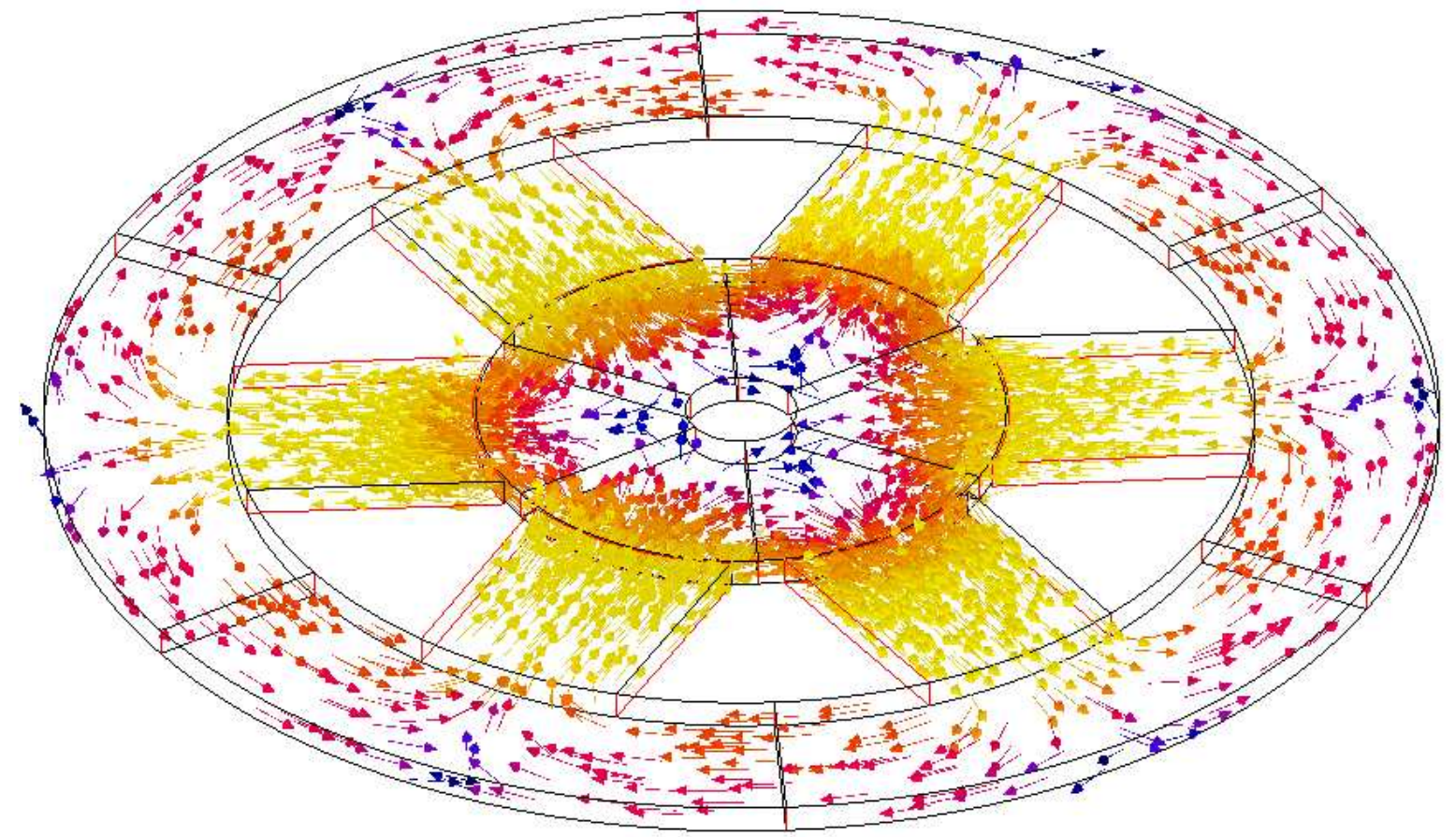

Fig. 6. Flux lines paths closing from the stator to the rotor. 
The construction technologies that can be used for the elaboration of the iron core of the MTTFRM are presented in the following paragraphs. Due to their important advantages, such is the 3D magnetic isotropy, soft magnetic composites, and in particular SOMALOY $700 \mathrm{HR}$, represent very good solutions for acquiring this objective.

For the construction of the proposed MTTFRM two types of ferromagnetic powder were used: SOMALOY $700 \mathrm{HR}$ process 1P supplied from Höganäs AB Sweden and ANCORBOND 45P, mixed with $0,5 \%$ in weight, KENOLUBE P11 supplied from Hoeganaes Corporation, Germany [11].

In order to obtain the best structure with the best properties various tests and comparisons were made. Multiple rings were obtained using the above mentioned powders in different working conditions: pressure, temperature, hardness. These parameters are given in Table 1 for the rings built using ANCORBOND 45P. A metallographic structure was obtained. The measured value of the iron core losses at a frequency of $100 \mathrm{~Hz}$ is a significant one.

Table 1. Value of the working parameters for the sintered rings from ANCORBOND 45P

\begin{tabular}{|c|c|c|c|}
\hline Parameter & Sample 1 & Sample 2 & Sample 3 \\
\hline Pressure [bar] & 170 & 190 & 210 \\
\hline Temperature [gr.C] & 1120 & 1125 & 1130 \\
\hline HRB Hardness & 32 & 46 & 61 \\
\hline
\end{tabular}

The best performances were obtained for the rings made of SOMALOY $700 \mathrm{HR}$. This material can stand a flux density of $2.1 \mathrm{~T}$ at a magnetic field of $100 \mathrm{kA} / \mathrm{m}$ and a relative magnetic permeability as high as 6000 can be achieved.

A three phase MTTFRM with passive mover, with two modules per phase, was built. Its main component parts are given in Fig. 7a. The whole machine is presented in Fig. 7b [12].

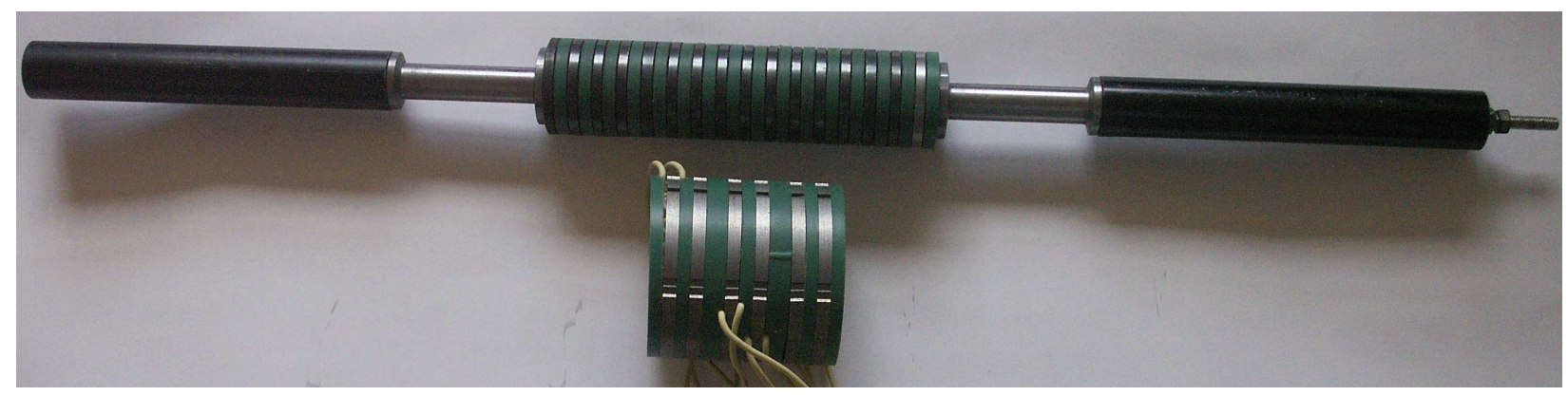

a)

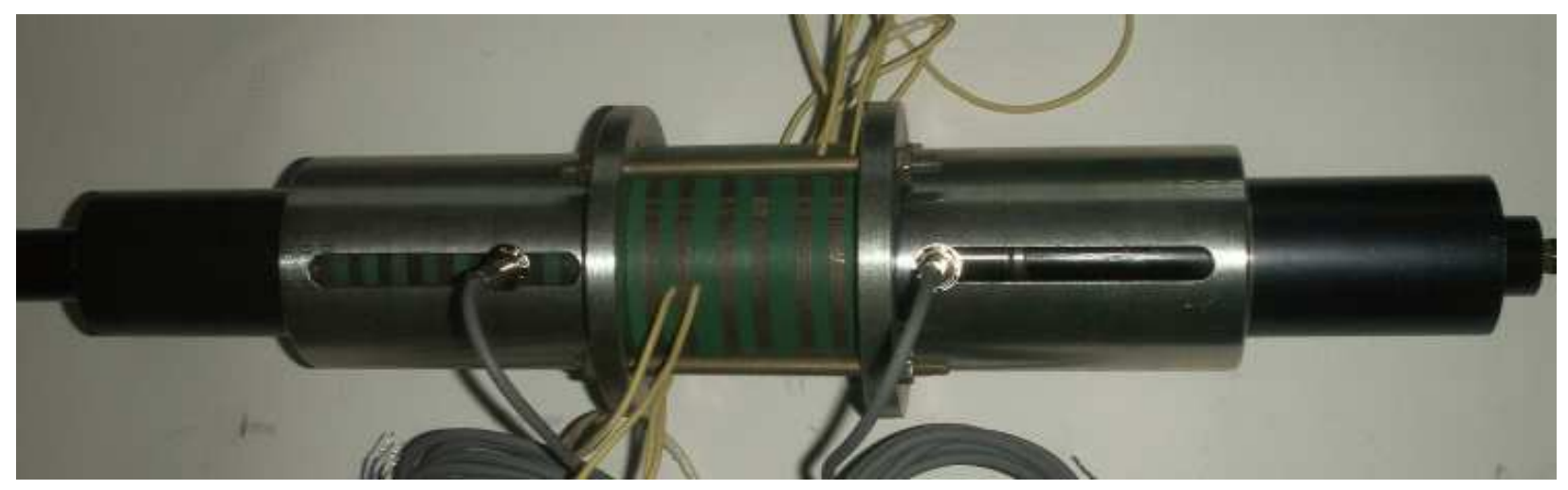

b)

Fig. 7. Structure of a three phase MTTFRM:

a) component parts; b) tubular machine. 


\section{Test bench with the MTTFRM Prototype}

For the command and control of this machine a buck converter in the front end is used in order to power supply the windings of a phase. The voltage that drops on the coils is controlled in this manner [13]. The machine being a three phase one, a classic converter from the market can be used here. It has the advantages of a simple structure and a relatively low cost.

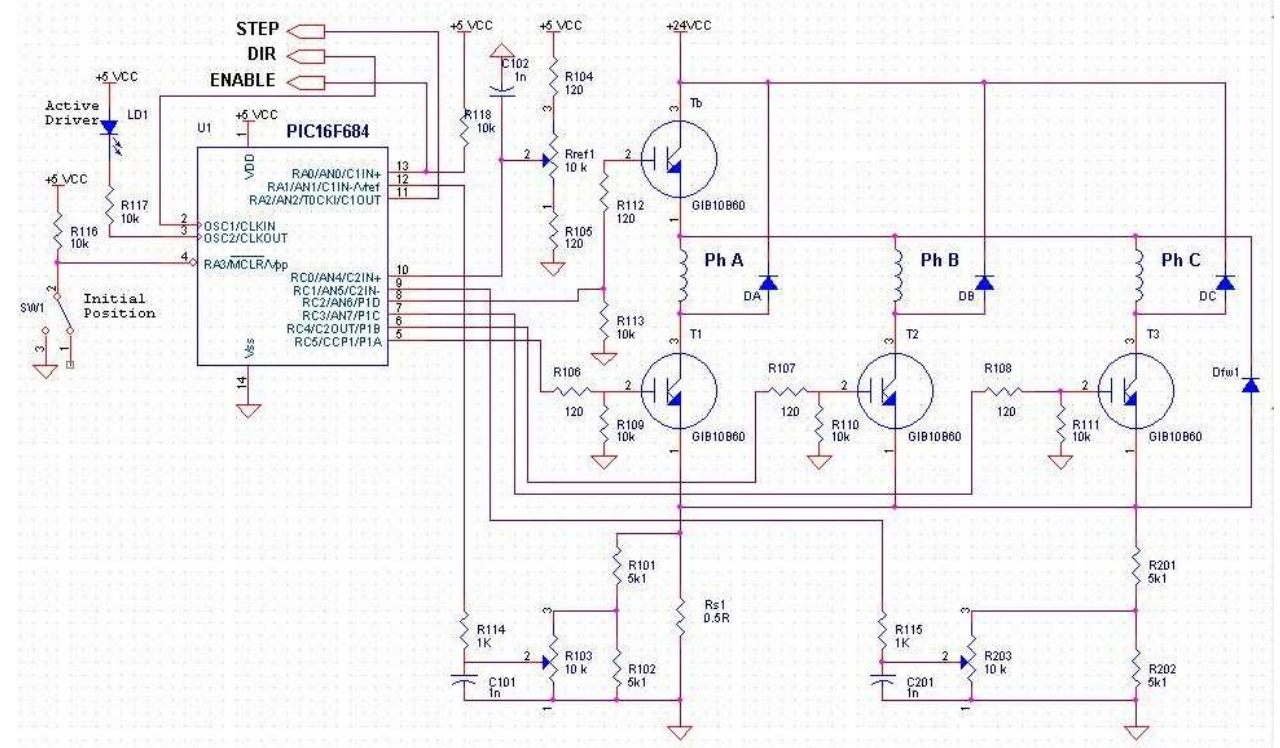

Fig. 8. Schematic diagram to be used in experimental tests

The driver used in the experimental work is an improved unipolar one, Fig. 8. The current is directed through each phase using a conventional converter that has an additional ground resistor $R_{s 1}$.

The built prototype shall be tested using a test bench, Fig. 9.

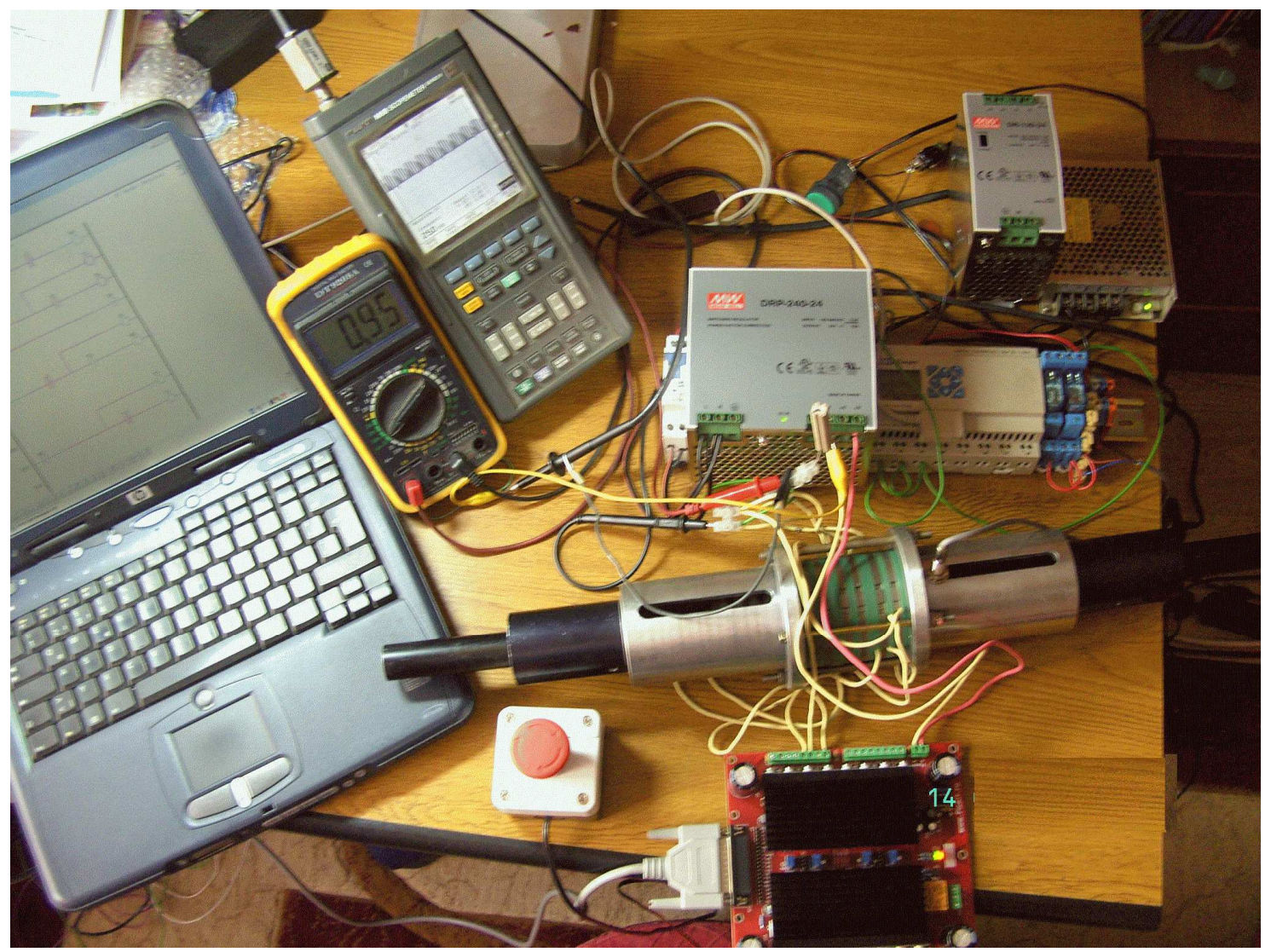

Fig. 9. Bench used for testing the prototype of MTTFRM 
The MTTFRM, equipped with inductive position sensors, is supplied from a dc power supply module that can provide the required level of voltage. In order to control the motor a converter module with current sensor and PWM and a programmable logic controller PLC are used.

In order to discharge the dynamic energy $[14,15]$ and to protect the motor from unexpected mechanical accidents a spring was placed at the mover ends. Separate magnetic springs can be used function of the application requirements [15]. In order to obtain a precise positioning of the mover dynamic braking must be considered. This can be done using adequate firing angle of IGBTs. This corresponds to the negative slope of the profile of inductance.

A good protection implies the use of a differential fuse and an Emergency Stop button.

\section{Conclusions}

The paper presents a new interesting type of tubular linear machine. It has a simple construction and major advantages are promissed by the unique properties of the new soft magnetic composite material, Somaloy $700 \mathrm{HR}$, particularly the 3D magnetic isotropy.

The innovative character of the construction is given by multiple aspects. The modular structure of the machine is a definitory characteristic. The possibility to build a phase of the machine by alternating magnetic pieces with non-magnetic spacers gives the advantage of obtaining machines with lower weight and price.

Both the topologies with active and passive mover were presented in the paper. Given the constructive advantages of the second variant, the study has focused on technology used for its construction and the presentation of a prototype built. A test bench intended to be used for experimental measurements was conceived and shown also here.

The preliminary computations promise a good force / mass ratio. Such tubular machines have drawn the attention of the specialists, promising to be potential solutions for precise industrial applications and various drives requiring short throw at a big range of speeds.

\section{Acknowledgment}

This paper was supported by the project "Development and support of multidisciplinary postdoctoral programmes in major technical areas of national strategy of Research - Development - Innovation" 4D-POSTDOC, contract no. POSDRU/89/1.5/S/52603, project co-funded by the European Social Fund through Sectoral Operational Programme Human Resources Development 2007-2013.

\section{References}

[1] D.C. Popa, L. Szabo, V.I. Gliga, V. Iancu, Design of a Novel Tubular Transverse Flux Reluctance Machine, Proceedings of the $8^{\text {th }}$ International Symposium on Linear Drives for Industry Applications (LDIA 2011), Eindhoven University of Technology, July 3-6, 2011, Eindhoven, Netherlands.

[2] D.C. Popa, V. Iancu, L. Szabó, Improved design of Linear Transverse Flux Reluctance Machine, Proceedings of the $11^{\text {th }}$ International Conference on Optimization of Electrical and Electronic Equipment Optim 2008, Brasov, Romania, pp. 137 - 142.

[3] J.F. Llibre, N. Martinez, B. Nogarede, P. Leprince Linear tubular switched reluctance motor for heart assistance circulatory: Analytical and finite element modeling, $10^{\text {th }}$ International Workshop on Electronics, Control, Measurement and Signals (ECMS), pp. 1-6 (2011).

[4] J.B. Wang, D. Howe - Analysis and Design Optimization of an Improved Axially Magnetized Tubular Permanent-Magnet Machine. IEEE Transactions on Energy Conversion, vol. 19, no. 2, pp. 289-295 (2004). 
[5] B.L.J. Gysen, J.J.H. Paulides and E.A. Lomonova, Direct-drive electromagnetic active suspension system with integrated eddy current damping for automotive applications, Proceedings of the $8^{\text {th }}$ International Symposium on Linear Drives for Industry Applications (LDIA 2011), Eindhoven University of Technology, July 3-6, 2011, Eindhoven, Netherlands.

[6] J.B. Wang; W. Wang; K. Atallah - A Linear Permanent-Magnet Motor for Active Vehicle Suspension, IEEE Transactions on Vehicular Technology, vol. 60, no. 1, Ian. 2011, pp. 55-63.

[7] J. Chiasson; S. Danbing; S. Fanping; A. Stankovic, S. Bortoff, Independent control of two PM motors using a single inverter: application to elevator doors, Proceedings of the 2002 American Control Conference, 2002, vol.4, pp. 3093 - 3098, 2002.

[8] J. Prudell, M. Stoddard, E. Amon, T. K. Brekken, Annette von Jouanne, A Permanent-Magnet Tubular Linear Generator for Ocean Wave Energy Conversion. IEEE Transactions on Industry Application, vol. 46, no. 6, November/December 2010, pp. 2392-2400.

[9] V. Delli Colli, R. Di Stefano, and M. Scarano, A tubular generator for marine energy direct drive applications, in Proc. IEEE Int. Conf. Electr. Mach. Drives, May 2005, pp. 1473-1478.

[10] Ioana Bentia, Contribution to the study of the rotary-linear switched reluctance motors, Ph.D. thesis, Technical University of Cluj-Napoca, 2012.

[11]http://www.hoganas.com/

[12]D.C. Popa, V.I. Gliga, L. Szabo, V. Iancu Tubular Transverse Flux Variable Reluctance Motor in Modular Construction, Proceedings of the 13th International Conference on Optimization of Electrical and Electronic Equipment (OPTIM '2012), pp. 572 - 577, 2012.

[13] H. Kobayashi, Y. Doi, K. Miyata, T. Minowa, Design of the axial-flux permanent magnet coreless generator for the multi-megawatts wind turbine, Proceedings of EWEC 2009, Parc Chanot, Marseille, France 16 - 19 March 2009.

[14] J.L.G. Janssen, J.J.H. Paulides, E.A. Lomonova, B. Delinchant, J.P. Yonnet, Design study on magnetic springs with low resonance frequency, Proceedings of the $8^{\text {th }}$ International Symposium on Linear Drives for Industry Applications (LDIA 2011), Eindhoven University of Technology, July 3-6, 2011, Eindhoven, Netherlands.

[15] J. Snamina, A. Posiadlo, P. Habel, Active vibroisolation system with magnetic springs, XXIV Symposium Vibrations in Physical Systems, Poznan - Bedlewo, May 12-15, 2010. 